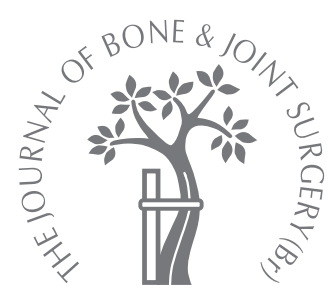

\title{
Gradual joint distraction of post-traumatic flexion contracture of the proximal interphalangeal joint by a mini-external fixator
}

S. Houshian,
C. Chikkamuniyappa,
H. Schroeder

From the University Hospital Lewisham, London, England and Odense

University Hospital, Odense, Denmark
In S. Houshian, MD, Consultant

Orthopaedic Surgeon

C. Chikkamuniyappa,

MS(Orth), DNB(Orth), Registrar

in Orthopaedics

Department of Orthopaedics

University Hospital Lewisham,

High Street, Lewisham, London

SE13 6LH, UK.

- H. Schroeder, MD,

Consultant Hand Surgeon

Department of Orthopaedics

Odense University Hospital,

Sdr. Boulevard 29, 5000

Odense, Denmark.

Correspondence should be sent to Mr S. Houshian; e-mail: shirzad.houshian@uhl.nhs.uk

(C)2007 British Editorial Society of Bone and Joint Surgery doi:10.1302/0301-620X.89B2. $18448 \$ 2.00$

$J$ Bone Joint Surg [Br] 2007;89-B:206-9.

Received 24 July 2006;

Accepted after revision 13

October 2006

We present the outcome of the treatment of chronic post-traumatic contractures of the proximal interphalangeal joint by gradual distraction correction using an external fixator. A total of 30 consecutive patients with a mean age of 34 years (17 to 54) had distraction for a mean of 16 days (10 to 22). The fixator was removed after a mean of 29 days (16 to 40 ).

Assessment at a mean of 34 months (18 to 54) after completion of treatment showed that the mean active range of movement had significantly increased by $63^{\circ}\left(30^{\circ}\right.$ to $\left.90^{\circ} ; \mathrm{p}<0.001\right)$. The mean active extension gained was $47^{\circ}\left(30^{\circ}\right.$ to $\left.75^{\circ}\right)$.

Patients aged less than $\mathbf{4 0}$ years fared slightly better with a mean gain in active range of movement of $65^{\circ}\left(30^{\circ}\right.$ to $\left.90^{\circ}\right)$ compared with those aged more than 40 years, who had a mean gain in active range of movement of $55^{\circ}\left(30^{\circ}\right.$ to $\left.70^{\circ}\right)$ but the difference was not statistically significant $(p=0.148$ ).

The use of joint distraction to correct chronic flexion contracture of the proximal interphalangeal joint is a minimally-invasive and effective method of treatment.

Post-traumatic flexion contracture of the proximal interphalangeal joint (PIPJ) is a common clinical problem and can lead to substantial functional deficit especially when it is severe or affects many fingers. ${ }^{1,2}$ Surgical treatment is demanding and the results are unpredictable. $^{2-5}$ However, recently, a minimallyinvasive technique using the principle of distraction histogenesis with external fixation has been reported with good short-term results. ${ }^{6,7}$

Our aim was to evaluate the clinical outcome of gradual distraction correction using a monolateral external fixator in a consecutive series of patients with chronic post-traumatic flexion contracture of the PIPJ.

\section{Patients and Methods}

Between September 2001 and September 2004, 32 patients with post-traumatic chronic flexion contracture of the PIPJ were included in the study. Two were subsequently lost to follow-up and the remaining 30 were available for assessment at one, three, six, and 12 months and at latest follow-up. The mean follow-up was 34 months (18 to 54).

There were 24 males and six females with a mean age of 34 years (17 to 54). The index finger was involved in five, the middle in two, the ring in seven and the little finger in 16 . The mean time from injury to operation was 20 months (6 to 84 ).
All had chronic flexion contractures either because of dislocation or fracture-dislocation involving the PIPJ (Fig. 1). Of the 30 patients, $19(63 \%)$ had a posterior PIPJ fracturedislocation with fractures of the volar lip, seven $(23 \%)$ had volar dislocation with a dorsal avulsion fracture and the remaining four (14\%) had a pure PIPJ dislocation without a fracture. All the intra-articular fractures, when present, involved less than a third of the articular surface, as assessed on the lateral radiographs.

All the patients had initial treatment for their fracture-dislocation in the form of a closed reduction and either neighbour strapping or a plaster of paris back slab. The patients were skeletally mature and none had previously undergone operative treatment, although all had received hand therapy with dynamic extension splints for a minimum of three months. Patients with contractures because of a burn or crush injury, or associated with a tendon laceration or chronic regional pain, were excluded from the study. Before surgery, the mean range of movement (ROM) of the PIPJ was $19^{\circ}\left(0^{\circ}\right.$ to $\left.50^{\circ}\right)$.

Operative technique. Under local or regional anaesthesia a unilateral dynamic mini Orthofix (Orthofix, Guildford, United Kingdom) external fixation device was positioned using image- 


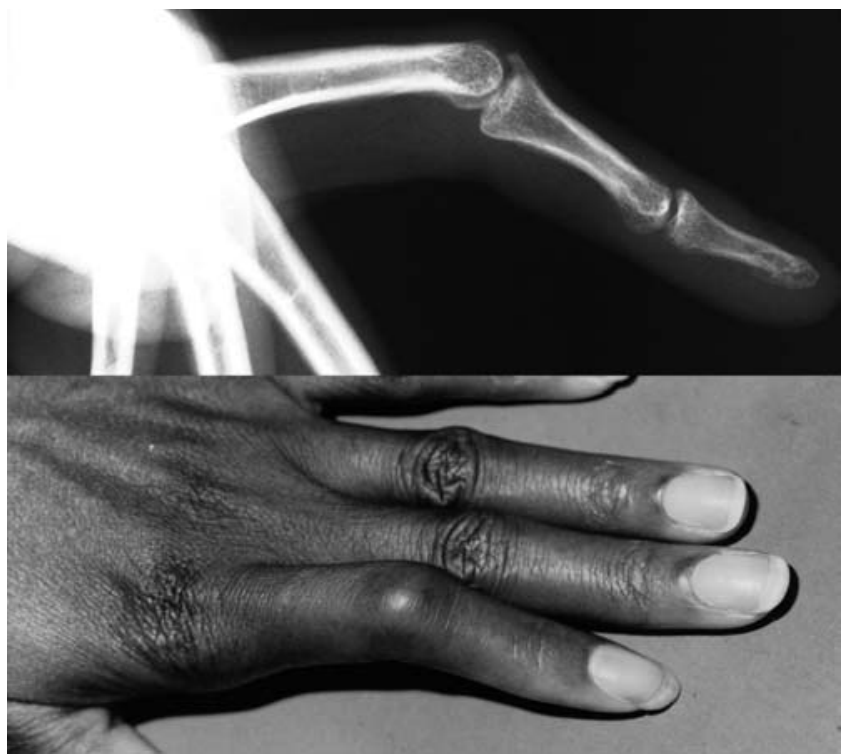

Fig. 1

Radiograph and photograph showing fixed-flexion deformity with contracture of the proximal interphalangeal joint of the index finger.

Table I. Post-operative mean $\left({ }^{\circ}\right.$; range) active range of movement

\begin{tabular}{lll}
\hline & Mean & \\
\hline At end of treatment & 19.33 & (0 to 50$)$ \\
At 1 month & 64.33 & $(40$ to 90$)$ \\
At 3 months & 82.00 & (50 to 100$)$ \\
At 6 months & 82.00 & (50 to 100$)$ \\
At final follow-up & 82.00 & $(50$ to 100$)$ \\
\hline
\end{tabular}

intensifier guidance (Fig. 2). The proximal and distal block fixations were attached to the proximal and middle phalanges respectively, using a single $2 \mathrm{~mm}$ threaded pin in each phalanx. The pins were placed parallel to each other and equidistant from the joint. The block and lengthening bar were placed on the volar aspect to provide both distraction and extension.

The fixator was positioned far enough away from the skin to accommodate swelling. The distraction nut was turned each day by a quarter turn (one full turn gave a joint distraction of $1 \mathrm{~mm}$ ) starting on the first day after surgery.

The patients were trained to do the distraction themselves at home and were reviewed weekly. The joint was distracted by a mean of $4 \mathrm{~mm}$ ( 3 to 5 ), as seen on lateral radiographs. When full extension was obtained (Figs 3 to 5 ) distraction was then maintained for a mean of 29 days (16 to 40 ).

The device was removed without anaesthesia in the outpatient clinic. No patient received prophylactic antibiotics. Hand therapy was undertaken for four weeks after removal of the fixator.

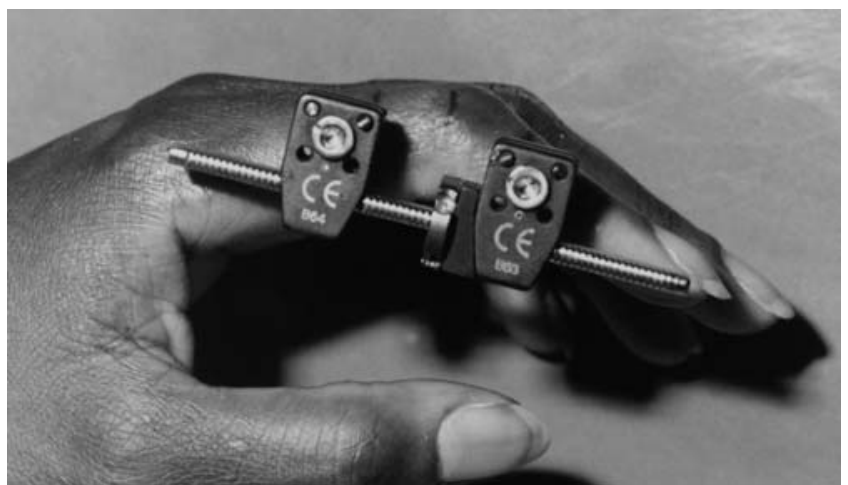

Fig. 2

Photograph showing the mini external fixator in situ.

During distraction, the neurovascular status of the finger was carefully monitored, especially when longer distraction was required for straightening of the PIPJ. The skin on the volar aspect of the joint was checked for pallor, and pain was also monitored during distraction. Many patients experienced some pain for a few minutes immediately after the distraction which then settled without the need for analgesia.

Statistical analysis. The statistical software packages SPSS 11.00 (SPSS Inc., Chicago, Illinois) and Systat 8.0 (Systat Software Inc., Richmond, California) were used for analysis of the data. Student's $t$-test (paired) was performed in order to determine significance in the improvement of the ROM. A p-value of $\leq 0.05$ was considered to be significant.

\section{Results}

The mean distraction time was 16 days (10 to 22 ) and the fixator was removed after a mean of 29 days (16 to 40 ). The wide range of distraction times reflects the difference in severity of the initial contracture and its duration before surgery. These two factors also influenced the duration for which the fixator was left in situ after full correction.

The mean active ROM gained by the procedure was $63^{\circ}$ $\left(30^{\circ}\right.$ to $\left.90^{\circ}\right)$; Student's $t$-test, $\mathrm{p}<0.001$; Table I. The mean active extension gained was $47^{\circ}\left(30^{\circ}\right.$ to $\left.75^{\circ}\right)$.

Patients aged less than 40 years fared slightly better with a mean gain in active ROM of $65^{\circ}\left(30^{\circ}\right.$ to $\left.70^{\circ}\right)$ compared with those aged more than 40 years, who had a mean gain in active $\mathrm{ROM}$ of $55^{\circ}$ (30 to 70 ), but the difference was not statistically significant $(\mathrm{p}=0.148)$.

At the final follow-up there were no recurrences and no loss of ROM. All patients were free from pain and were satisfied with the functional and cosmetic results (Fig. 6).

Complications included superficial pin-track infection in five patients $(17 \%)$ which settled within seven days with oral antibiotics and local wound care. Nine patients 


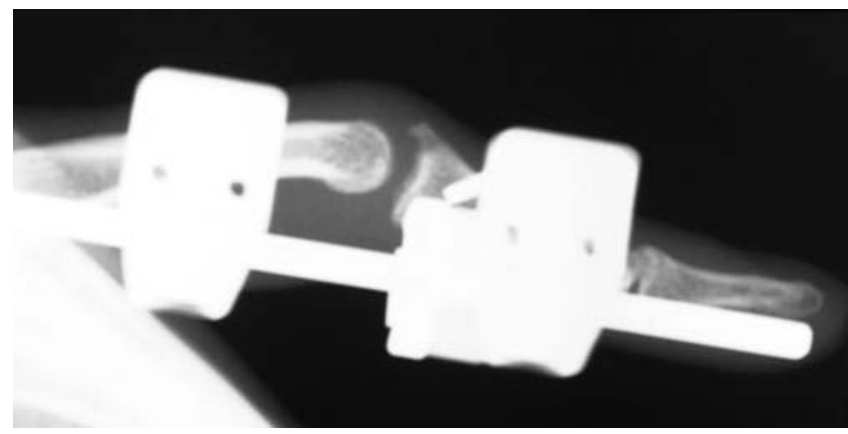

Fig. 3

Radiograph showing a lateral view of the index finger with $2 \mathrm{~mm}$ joint distraction four days after application.

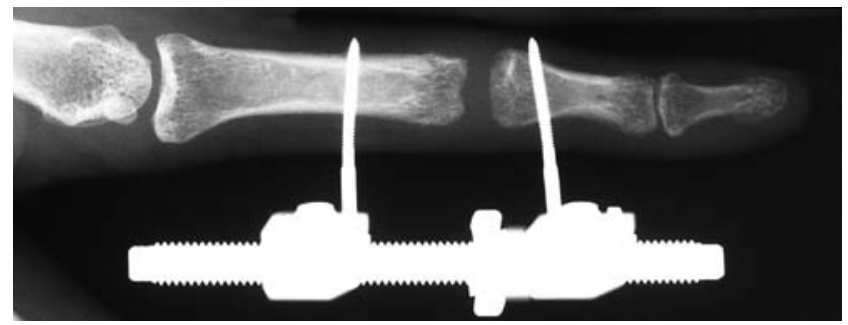

Fig. 4

Radiograph showing an anteroposterior view of the index finger with $5 \mathrm{~mm}$ joint distraction ten days after application.

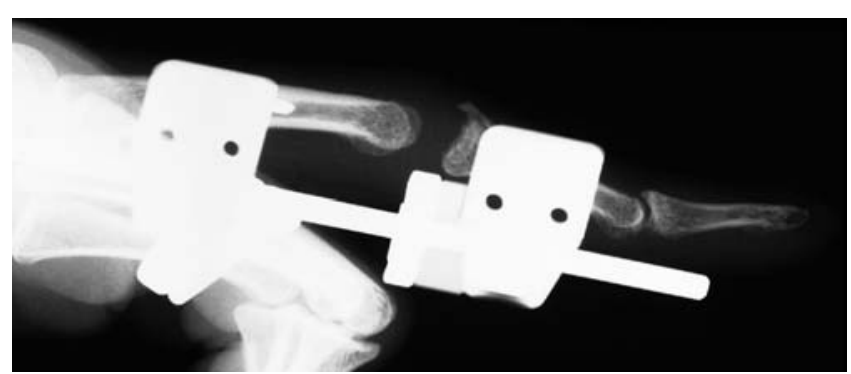

Fig. 5

Radiograph showing a lateral view of the index finger with $5 \mathrm{~mm}$ of joint distraction 12 days after application.

$(30 \%)$ had slight pain at the beginning of distraction, but all could tolerate the procedure well without interruption of the treatment.

We did encounter a temporary flexion deformity of the distal interphalangeal joint after distraction probably because of tension of the flexor tendon. This resolved after hand therapy following removal of the fixator.

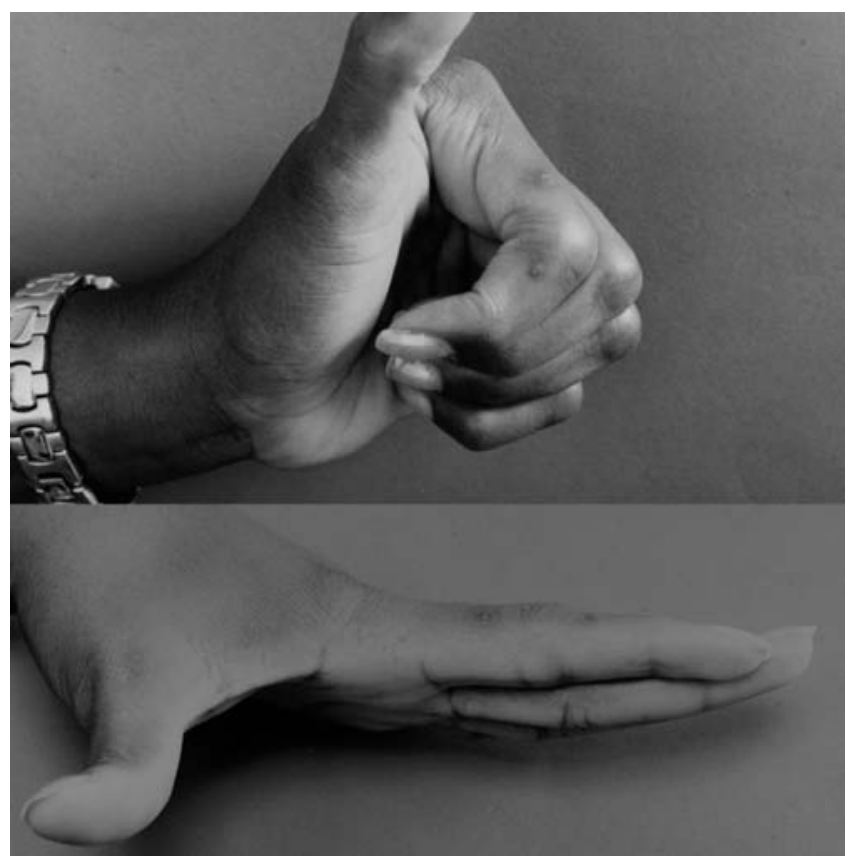

Fig. 6

Photographs showing flexion and extension of the proximal interphalangeal joint at follow-up at one year.

\section{Discussion}

The standard treatment for chronic post-traumatic flexion contracture of the PIPJ which is resistant to conservative management has been open surgery. Curtis 8,9 described sequential capsular release and subsequently several other surgeons have reported alternative open techniques with variable rates of success. Sprague ${ }^{3}$ reported a gain of only $13^{\circ}$ in the arc of movement after capsular release which subsequently deteriorated and became worse than the preoperative value at follow-up at one year. In 1977 Harrison ${ }^{10}$ proposed a modification of Curtis' method by preserving the collateral ligaments and reported a gain in the arc of movement of $24^{\circ}$.

Gould and Nicholson ${ }^{11}$ reported improvement of $12^{\circ}$ to $13^{\circ}$ after volar capsulectomy. Mansat and Delprat ${ }^{12}$ used arthrolysis for release of flexion contracture and noted an improvement of $18^{\circ}$ while Bruser et $\mathrm{al}^{1}$ reported improvement of $30^{\circ}$ to $50^{\circ}$.

Ghidella et $\mathrm{al}^{2}$ presented the long-term results using Curtis' technique and reported a mean gain of $8^{\circ}$. However, $31 \%$ of their patients required further surgery and they concluded that patients should be carefully evaluated before surgery and a strict selection policy applied.

Although the principle of distraction histogenesis is well established, its application in correcting flexion contracture of the PIPJ by external fixation has only recently been documented in the literature. ${ }^{6,7,13,14}$ In 1986 , Schenck ${ }^{15}$ was probably the first to use external fixation and early passive mobilisation for fracture and dislocation around the PIPJ. 
Hastings and Carrol, ${ }^{16}$ Inanami et al, ${ }^{17}$ Patel and Joshi ${ }^{18}$ and Fahmy ${ }^{19}$ have also reported the use of distraction with subsequent mobilisation in the management of chronically dislocated PIPJs. Richtr and Rysavy ${ }^{20,21}$ used the VolkovOganesjan distraction-reposition apparatus in six patients with flexion-contracture of the PIPJ. An improvement in the ROM of $48^{\circ}$ was obtained at a follow-up of three months. Hodgkinson ${ }^{22}$ described the use of skeletal traction before definitive surgery to correct contracture in patients with advanced Dupuytren's disease and Bain et $\mathrm{al}^{23}$ used a compass-hinge fixator for flexion-contracture, reporting a good result in two cases. Kasabian, McCarthy and $\mathrm{Karp}^{24}$ in 1998 described the use of a multiplanar distractor in a single patient with a PIPJ contracture after replantation. Houshian, Gynning and Schroeder ${ }^{25}$ used a similar compass hinge for dynamic extension correction in 27 patients, and reported a mean extension gain of $38^{\circ}$ with a mean arc of movement of $42^{\circ}\left(0^{\circ}\right.$ to $\left.80^{\circ}\right)$. Da Silva et $\mathrm{al}^{26}$ reported distraction correction of a long-standing (20 years) flexion contracture, using a lengthening device, with a good result.

In theory, distraction correction differs from extension correction using the compass hinge, in that the soft-tissue contractures have an increased chance of correction when the joint is subjected to gradual distraction. We have previously reported good short-term results using a monolateral Orthofix frame for distraction in ten patients with a mean gain in ROM of $54^{\circ}$ at six months. ${ }^{6}$ Ravishankar ${ }^{7}$ used a bilateral frame (Joshi's fixator) for correcting post-burn contracture of the PIPJ.

Loss of movement over time after the procedure has been a problem in previous studies. ${ }^{3}$ Ghidella et $\mathrm{al}^{2}$ stated that there was probably little difference in the expected outcome after 24 months. In our series there was little difference between the result at six months and that at the last followup and there were no recurrences.

Ghidella et $\mathrm{al}^{2}$ discouraged attempts at correction of the contracture of the PIPJ in patients over 43 years of age. Their ideal patient was 28 years of age and had a maximum flexion contracture of $43^{\circ}$. The mean age of our patients was 34 years (17 to 54 ) and nine patients were more than 40 years of age. We found no difference in outcome for patients aged over and under 40 years.

We had no serious complications, although pin-track infection occurred in five patients.

There are two areas which require further investigation. The first is the amount of distraction required and the stage at which permanent damage ${ }^{1}$ occurs. Patel and Joshi ${ }^{18}$ reported joint distraction of $5 \mathrm{~mm}$ for optimum reduction of the dorsal dislocation. We have not had any adverse effects from distraction of $5 \mathrm{~mm}$, perhaps because the distraction is applied gradually. In addition, we did not encouter any lateral instability of the PIPJ. The second point is the timing of removal of the fixator. We left it in situ for a mean of 29 days (16 to 40) after full correction of the deformity. This allowed the stretched tissues to mature in their new position and inflammation to subside.

In summary, joint distraction using a monolateral external fixator for correction of flexion contracture of the PIPJ offers an effective method of treatment, but we suggest that randomised, controlled studies are now required.

\section{Supplementary Material}

$\because$ A table showing the clinical details of the patients in this study is available with the electronic version of this article on our website at www.jbjs.org.uk

No benefits in any form have been received or will be received from a commercial party related directly or indirectly to the subject of this article.

\section{References}

1. Bruser P, Poss T, Larkin G. Results of proximal interphalangeal joint release for flexion contractures: midlateral versus palmar incision. J Hand Surg [Am]1999;24:288-94.

2. Ghidella SD, Segalman KA, Murphey MS. Long-term results of surgical management of proximal interphalangeal joint contracture. J Hand Surg [Am] 2002;27:799-805.

3. Sprague BL. Proximal interphalangeal joint contractures and their treatment. J Trauma 1976;16:259-65.

4. Foucher G, Lenoble E, Ben-Youssef K, Sammut D. A post-operative regime after digital flexor tenolysis: a series of 72 patients. J Hand Surg [Br] 1993;18:35-40.

5. Koller VR, Choi MS, Bayer GS, Millesi H. Analysis of change in finger function after flexor tenolysis. Handchir Mikrochir Plast Chir 1996;28:204-9 (in German).

6. Houshian S, Schroeder HA. Distraction with external fixator for contractures of proximal interphalangeal joints: good outcome in 10 cases. Acta Orthop Scand 2004;75:225-8.

7. Ravishanker R. Distraction correction for flexion contractures of the fingers: a minimally invasive technique. Indian J Plastic Surg 2003;36:99-103.

8. Curtis RM. Capsulectomy of the interphalangeal joints of the fingers. J Bone Joint Surg [Am] 1954;36-A:1219-32.

9. Curtis RM. Management of the stiff proximal interphalangeal joint. Hand 1969;1:32-7.

10. Harrison DH. The stiff proximal interphalangeal joint. Hand 1977;9:102-8.

11. Gould JS, Nicholson BG. Capsulectomy of the metacarpophalangeal and proximal interphalangeal joints. J Hand Surg [Am] 1979;4:482-6.

12. Mansat M, Delprat J. Contractures of the proximal interphalangeal joint. Hand Clinic 1992;8:777-86.

13. Messina A, Messina J. The continuous elongation treatment by the TEC device for severe Dupuytren's contracture of the fingers. Plast Reconstr Surg 1993;92:284-90.

14. Citron N, Messina J. The use of skeletal traction in the treatment of severe primary Dupuytren's disease. J Bone Joint Surg [Br] 1998;80-B:126-9.

15. Schenck RR. Dynamic traction and early passive movement for fractures of the proximal interphalangeal joint. J Hand Surg [Am] 1986;11:850-8.

16. Hastings H 2nd, Carrol C 4th. Treatment of closed articular fractures of the metacarpophalangeal and proximal interphalangeal joints. Hand Clinic 1998;4:503-27.

17. Inanami H, Ninomiya S, Okutsu I, Tarui T. Dynamic external fixator for fracture dislocation of the proximal interphalangeal joint. J Hand Surg [Am]1993;18:160-4.

18. Patel MR, Joshi BB. Distraction method for chronic dorsal fracture dislocation of the proximal interphalangeal joint. Hand Clin 1994;10:327-37.

19. Fahmy NR. The Stockport Serpentine Spring System for the treatment of displaced comminuted intraarticular phalangeal fracture. J Hand Surg [Br] 1990;15:303-11.

20. Richtr M, Rysavy M. Use of the Volkov-Oganesjan distraction-reposition apparatus in treatment of flexion contractures of the interphalangeal joints. Acta Chir Orthop Traumatol Cech 1991;58:9-19 (in Czech).

21. Richtr M, Rysavy M. Use of a distraction apparatus in the treatment of flexion contractures in the interphalangeal joints. Rozhl Chir 1992;71:169-73 (in Czech).

22. Hodgkinson PD. The use of skeletal traction to correct the flexed PIP joint in Dupuytren's disease: a pilot study to assess the use of the Pipster. J Hand Surg [Br] 1994;19:534-7.

23. Bain GI, Janak AM, Heptinstall RJ, Bria M. Dynamic external fixation for injuries of the proximal interphalangeal joint. J Bone Joint Surg [Br] 1998;80-B:1014-19.

24. Kasabian A, McCarthy J, Karp N. Use of a multiplanar distracter for the correction of a proximal interphalangeal joint contracture. Ann Plastic Surg 1998;40:378-81.

25. Houshian S, Gynning B, Schroeder HA. Chronic flexion contracture of proximal interphalangeal joint treated with the compass hinge external fixator: a consecutive series of 27 cases. J Hand Surg [Br]2002;27-B:356-8.

26. da Silva P, Barbosa R, Ferreira P, et al. Correction of long term joint contractures of the hand by distraction: a case report. Br J Plast Surg 2005;58:1148-51. 